\title{
Departamento \\ de Geografia: linhas \\ de pesquisa
}

ANTONIO CARLOS ROBERT MORAES

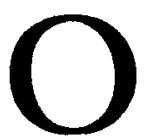

título que Paulo Arantes colocou em seu livro sobre o Departamento de Filosofia da Universidade de São Paulo - Um departamento francts de ultramar - ajusta-se com toda propriedade para uma caracterizaçáo do vizinho Departamento de Geografia - DG. Fundado por mestres franceses, tendo por modelo a estrutura dos departamentos/cátedras em que estes se formaram e por doutrina o possibilismo lablacheano, o DG jamais conseguiu sair da órbita de influência da geografia produzida em França. Sequer conseguiu assimilar, mesmo que marginalmente, outras orientaçóes teóricas. Do mesmo modo que a geografia francesa, a geografia brasileira pensou-se como uma extensão da Escola Normal, tendo por público-alvo o docente do ensino fundamental. Também como esta incorporou fenomenal simpatia pelo empirismo, elegendo por modelo básico de pesquisa a monografia regional. Igualmente como a matriz, por longo tempo, o DG enganou-se entendendo seu campo de reflexáo como um saber positivo e apolítico, que tranqüilamente transitava entre os fenômenos naturais e sociais. $\mathrm{O}$ apreço pela história aparece, nesse quadro, como uma das poucas virtudes de berço, também herdada da influência fundante (que o professor Pasquale Petrone sempre salientou para seus alunos).

Até a atualidade este cordão umbilical permanece atado, se bem que - também nisso seguindo a matriz - as influências teóricas da escola parulista de geografia se multiplicaram bastante, rompendo com certo provincianismo antes imperante. Tanto em França quanto aqui, os anos sessenta germinaram certa ruptura com os paradigmas tradicionais, tendo como destaque uma politização do discurso geográfico. Nas décadas seguintes - tanto lá quanto aqui - esse discurso trafegou para níveis crescentes de radicalismo, nos quais, em certo momento, o maoísmo pareceu ser a orientação dominante (fato facilmente explicável pela tradição disciplinária assumida, profundamente marcada por certo pendor agrarista já na origem). $O$ desenrolar da década de oitenta trouxe, 
contudo, algumas surpresas, entre elas o despertar do movimento ambientalista, a retomada da discussão geopolítica e a revivência do planejamento urbano. Grosso modo, pode-se dizer que estes três universos temáticos recobrem a maior parcela da produção atual dos geógrafos uspianos e também da geografia francesa como um todo. Nem poderia ser de outro modo, à medida em que até a atualidade o fluxo de relaçōes (intercâmbios, bibliografias etc.) entabulado pelo DG ainda flui primordialmente para a França.

De novidade, vale ressaltar a cada vez mais rápida sintonia de ajuste para com os paradigmas centrais, que a aceleraçáo da velocidade da informação e a globalizaçăo contemporânea da ciência como um todo impóem. Além disso, vale também apontar que ocorreu uma profunda autonomização temática da produção geográfica uspiana, alimentada de um lado pela própria herança empirista do possibilismo c, de outro, pela priorização dos problemas nacionais advinda da progrersiva politização da comunidade dos geógrafos. Tal produçáo, ao não conflitar no geral com a fundamentaçáo e objetivos teóricos do centro, propicia inclusive o início de um contrafluxo na difusão de conhecimento. Enfim, o conhecimento produzido hoje no Departamento de Geografia da USP revela ainda muito da influência teórica francesa, porém já é plenamente autocentrado em termos da definiçăo de sua agenda de pesquisa. $\mathrm{Na}$ confluência dessas qualidades emerge o perfil da produção departamental, com suas virtudes e defeitos.

O progressivo predomínio da geografia urbana é uma das características desse perfil na atualidade, que se diferencia da situaçáo de predominância dos estudos de geografia agrária até passado razoavelmente recente. Tal dominância se faz acompanhar de refinamento metodológico e de motivaçáo teórica desconhecidos na produçáo departamental mais antiga, de cunho marcadamente empirista. Pode-se dizer que toda a ampla agenda de subtemas da geografia urbana é hoje trabalhada no Departamento de Geografia, desde o estudo das funçōes urbanas e da economia política da urbanizaçáo até os que enfocam a estruturação interna do espaço urbano e suas formas de representação e vivência. Os fenômenos da metropolizaçáo e da verticalizaçăo estão contemplados em linhas de pesquisa que avançam para comparaçóes latino-americanas. Os processos de favelização e autoconstrução, por exemplo, já foram objeto de análises detalhadas no âmbito do DG.

É interessante observar que esta predominância da temática urbana na produçáo da geografia uspiana acompanha a tendência de comportamento da própria estruturação territorial do país, que tem atualmente quase oitenta por cento de sua populaçăo vivendo em cidades. $\mathrm{Na}$ 
verdade, o dinamismo hiperveloz do processo de urbanizaçāo no país não poderia passar desapercebido para um corpo de pesquisadores dos quais uma das marcas de formação era exatamente a atenção dada à realidade nacional. Entender o Brasil passa necessariamente pela compreensão da articulação de sua rede de cidades, e captar o movimento de sua sociedade requer que se conheça primordialmente a vida citadina. Portanto, a agenda atual do DG parece bem contemplar as questóes para as quais o presente diz: that is the question.

Por ser a cidade o locus básico da modernidade, os estudos de geografia urbana desenvolvidos no DG acabaram por resvalar para a discussão da difusão da técnica no espaço, o que implica ver as cidades como nós das redes de mundialização contemporâneas. Tal ótica orienta o que pode ser definido como uma área de preocupaçóes emergente na agenda da pesquisa departamental. O estudo dos fluxos e da distribuiçáo dos equipamentos de ponta adquire relevo nessa perspectiva, elegendo temas como, por exemplo, os tecnopólos ou a espacialidade dos sistemas informacionais. Tal linha emergente também contempla a análise da globalizaçáo e das relaçóes internacionais Nesse particular, atençáo especial vem sendo dada ao estudo da integração latino-americana, notadamente no que importa à consolidação do Mercosul. Uma política de incremento das relaçóes bilaterais com outros departamentos de geografia da América Latina e a realização de, pelo menos, um evento internacional por ano bem expressam o propósito departamental de reforçar essa área emergente.

O segundo grande campo de interesse da pesquisa departamental na atualidade é o da geografia política, que em si mesmo já incorpora algo da área emergente já descrita. É interessante observar que, do mesmo modo que a geografia urbana acaba por desalojar os estudos agrários antes predominantes, a geografia política se sobrepóe paulatinamente a um espaço antes ocupado pela temática regional. Esta passa a ser vista como um fator a mais a ser considerado pelo novo campo. Na verdade, a geografia política é tão velha quanto a própria geografia humana, porém nunca conheceu destaque significativo na geografia francesa e foi quase ignorada pelos geógrafos uspianos até data recente. $O$ eixo forte da geografia francesa sempre pendeu para uma abordagem mais econômica (inclusive mais palatável frente às premissas da neutralidade científica assumidas) e tal característica reproduziu-se neste departamento de ultramar.

O destaque dado à geografia política - também nisso acompanhando a agenda contemporânea da geografia francesa - responde, entretanto, a questóes cruciais postas para a sociedade brasileira. De um 
lado, tem-se o emergir de nova ordem internacional, implicando nova divisão da produção em termos globais e nova hierarquia entre países e lugares. Encontrar os caminhos e o papel do Brasil face a esse cenário em mutação aparece como essencial para o destino nacional, e os estudos geográfico-políticos permitem que se obtenha indicadores preciosos acerca dessa matéria. De outro lado, persistem questóes de ordem geopolítica internas que também animam pesquisas interessantes. Pode-se dizer que uma tensão federativa atravessa o ordenamento institucional do país, revelando que a distribuição interna do poder político ainda não encontrou seu ponto de equilíbrio. Assim, temas como a descentralização administrativa, o municipalismo ou a regionalização, por exemplo, emergem como importantes face às demandas colocadas pela meta de democratização do Estado.

Além destes dois grandes campos de interesse - a geografia urbana e a geografia política - a agenda de pesquisa do DG ainda contempla outros núcleos menores de preocupação dentro do amplo horizonte da geografia humana. A própria geografia agrária conhece vigorosa linha de investigação dedicada ao mapeamento dos conflitos de terra no país e à análise da sociabilidade camponesa. Outro núcleo a se destacar é aquele dedicado aos estudos de metodologia e história da geografia, que no presente envereda pela análise da constituiçăo da comunidade de geógrafos no Brasil e de suas formas de legitimaçăo acadêmica. Isoladamente ainda se observam trabalhos dedicados à geografia dos gêneros, do turismo e cultural.

Até aqui falou-se das linhas de pesquisa localizadas no campo da geografia humana; o DG, todavia, possui longa e sólida tradição de estudos de geografia física. Estes, tradicionalmente foram concebidos em perspectivas articuladoras e sintéticas, dentro daquela orientaçáo que pode ser denominada de geografia física global. Assim, os trabalhos tópicos desenvolvidos nas áreas da geomorfologia, climatologia ou biogeografia sempre apontaram para uma ótica de fisiologia da paisagem bem expressa, por exemplo, no conceito de domínios morfoclimáticos (tão bem trabalhados pelo professor Aziz Ab'Saber). Por essa razão, principalmente, a pesquisa departamental em geografia física rapidamente assimila as demandas colocadas pelos paradigmas ambientais da atualidade.

As pesquisas na área de meio ambiente constituem atualmente o carro-chefe do trabalho departamental no campo da geografia física. $\mathrm{Na}$ verdade, o trabalho do DG pode ser considerado um dos pioneiros nesta área no Brasil (bastando lembrar os desenvolvidos pelo Laboratório de Climatologia, já no início dos anos setenta). A importância do estudo de 
tal temática para o país é evidente, bastando lembrar que o rearranjo mundial contemporâneo estrutura-se em muito tendo por eixo a exploração das vantagens comparativas de cada lugar, e, nesse sentido, a biodiversidade $e$ as perspectivas de desenvolvimento sustentável aparecem como fortes qualidades brasileiras, cuja efetivação demanda um conhecimento profundo do comportamento dos diferentes ecossistemas presentes no território nacional.

Vários tópicos constantes da agenda da pesquisa ambiental sáo trabalhados no DG, desde os levantamentos sistemáticos de solo, vegetaçăo, clima e relevo, até a avaliaçáo do impacto da ação antrópica sobre cada um desses componentes do meio físico. A cartografia ambiental conhece razoável destaque nessa pauta de pesquisas, seja em tratamento mais teórico (buscando uma semiologia cartográfica) seja em seus rebatimentos práticos (por exemplo, em seu uso nas açóes de zoneamento ambiental). Enfim, dentro desse amplo horizonte de investigaçăo na área de meio ambiente emerge uma variedade de estudos considerável. O meio urbano, por exemplo, conhece uma interessante linha de pesquisa centrada no campo da climatologia. No que tange aos levantamentos sistemáticos, o Laboratório de Pedologia do DG já se firmou como um centro de referência nacional no estudo de solos. A incorporaçăo de tecnologia de ponta, envolvendo o sensoramento remoto $\mathrm{e}$ a interpretaçáo de imagens de satélite, também consta da agenda departamental de pesquisa.

Restaria apenas comentar, também como área emergente, a aproximaçáo rica entre a geografia e o campo pedagógico. E interessante observar que, apesar de eleger o docente do ensino básico como seu público-alvo fundamental, o DG não priorizou os estudos sobre o ensino da geografia em sua agenda de pesquisa até tempos bem recentes. $O$ divórcio entre a licenciatura e o bacharelado era bastante nítido, deixando a descoberto toda uma reflexáo sobre a didática geográfica e seu relacionamento com a filosofia da educaçăo. $\mathrm{Na}$ atualidade, tal diálogo vem sendo retomado de forma mais sistemática através tanto da reflexáo crítica acerca do livro didático e da praxis docente quanto da geraçáo de técnicas para o aprendizado dos temas da geografia escolar (com destaque para o uso do instrumental cartográfico nesse trabalho).

De forma sucinta, são estas as linhas de pesquisa trabalhadas pelo DG no presente. Face a um critério de relevância social, os temas eleitos pelo departamento se justificam plenamente. Também em termos da excelência acadêmica e no plano das comparaçóes internacionais, o temário trabalhado possui amplo respaldo. Como ponto fraco existente, pode-se apontar a baixa institucionalidade da maior parte das equipes de 
pesquisa, praticamente restritas às atividades da pós-graduação (o que acarreta descontinuidade e assistematicidade no trabalho). Por isso, vale salientar que o potencial existente de geração de conhecimento não foi ainda plenamente explorado.

Antonio Carlos Robert Moraes é professor do Departamento de Geografia da Faculdade de Filosofia, Letras e Ciências Humanas da USP. 